\title{
Present Scenario of Medical Education in the State and the Country
}

\section{Vithalrao Dandge*}

R.D. Gardi Medical College, Ujjain (MP), India

*Corresponding author: Vithalrao Dandge, R.D. Gardi Medical College, Ujjain (MP), India, Tel: +7368261304; E-mail: dandge_vp@yahoo.com

Received date: July 27, 2016; Accepted date: July 29, 2016; Published date: August 05, 2016

Copyright: (c) 2016 Dandge V. This is an open-access article distributed under the terms of the Creative Commons Attribution License, which permits unrestricted use, distribution, and reproduction in any medium, provided the original author and source are credited.

\section{Editorial}

"Aharnish Sevamahe" vguẾk lsokegs "Eternally in Service of Mankind at every moment". This is the motto of my life.

India will be the largest producer of Medical Graduates. In other words every Indian medical graduate will be responsible for the health of the world. We in India are keen on improving the state of affairs of Medial Education in our Country and health services for every citizen of our country.

Being prepared for change is an attribute of the educated and enlightened. Illiterate in the 21 st century, are not always those who cannot read or write; but more often they are those who do not want to 'change' or do not want to accept change. Medical Education has seen tremendous change in both content and delivery. The system is in place and people in the hierarchy of transforms in the education system have time and again incorporated the subtle changes necessary.

So if we need to stand before the growing demands of the complexities of these changes, we need not make many efforts to change the system as much the attitude of people towards this change.

\section{Priority Areas}

Today Medical education in the state and in the country as a whole is at cross roads. In these circumstances, we should pay attention to some priority areas. On one hand, we have made rapid advances in the field of medical education, restructuring of curriculum and opening of new medical colleges to meet the shortfall of medical graduates in the country. On the other hand our qualitative performance as compared to international standards is still a far cry from the desired figures. The reasons are multiple but strong individuals with a vision and strong universities can bring about a transformation in the desired direction. For this to happen, among other interventions, selection of the proper person, empowering the chair of Vice Chancellor (Medical University) and a pragmatic approach to medical education is of utmost priority. Due to paucity of a strong leadership and coordination amongst the different stakeholders (Health Administrators, Health educationists, Planners and Politicians), various problems are being created in the basic requirements of undergraduate and postgraduate medical education.

The resent slump in the demand for the medical seats is an indicator of problems in the field of medical education and also in the area of employability. I personally feel our curriculum teaching modules, teaching methodologies and training programs need a thorough revamping which would be acceptable to most, and attractive to the student community. It is not necessary always to imitate the western model of medical education but to evolve our own model, depending upon our present needs and future demands. One of the grey areas in this field is lack of Centre-State coordination regarding this matter, and lack of proper coordination and mutual understanding amongst different Health Universities of India. Other areas which need to be addressed are uniformity within the state and also amongst other states in the country, standardization of admission and examination procedures in the state and the country, gradation as per laid down standards of medical institutions and developing a competent effective dedicated army of medical teachers through a screening process which needs to be formulated. These are few of the priority areas which need to be focused and worked upon for the betterment of medical education in the state and the country.

\section{Pitfalls}

Basically the pitfalls in the current medical education are due to overenthusiasm in starting more medical colleges particularly in private sector. Here we have got some written standards and criteria to start a private medical college; they are on papers. In reality, if you really, neutrally inspect, that too with an element of sudden inspection or surprise inspection, then the state of affairs in private medical colleges whatever is shown to MCI and other universities and controlling bodies are definitely not up to standards. And I can give you many examples wherein the infrastructure in about only $70-80 \%$ colleges is good but not up to the mark. Infrastructure means I mean the buildings and equipment to some extent but other infrastructure, like medical teachers and subordinate staff to run the medical college properly are lacking very pitiably. For example, as for MCI norms, I know the earlier norms are reduced to very dangerous levels now a day in anatomy physiology pathology and many clinical subjects. But still with these reduced norms also, you examine any private medical college - there might be a few exceptions to this rule - but there are no devoted full time staff really available in these private medical colleges. If somebody claims that yes we are showing on papers, yes it is true that they are full time but on paper only. Really this is a sorry state of affairs, all those full time teachers specially in clinical, some para clinical and non-clinical areas, they are allowed private practice after the college hours, but unfortunately part of this is that they are doing all such practices in the college timing and no authority can stop this because when you start showing discipline to such people they threaten to resign from the institute and we do not have a good number of medical teachers who can devote full time in their place.

Another issue is students' attendance. Basically there are several pitfalls in this area too partly because of inadequate number of medical teachers and non-interested medical teachers who are not interested in taking the classes - theory or clinical - as per the norms laid down. I have seen at many private medical colleges that clinic goes for 35 to 45 min which should be there for two and half to three hours. Sometimes the students wait for hours together that their teacher will come and teach, but ultimately they leave the class.

This is the interrelated problem. The teachers are not there, so students are not coming, the students are not there so some sincere 
Citation: Dandge $\vee(2016)$ Present Scenario of Medical Education in the State and the Country. J Neonatal Biol 5: e118. doi:

Page 2 of 2

teachers too are becoming disinterested in taking the classes. Because basically they come for the class very sincerely and there are no students.

Especially in the private medical colleges, the students who come, majority of them are from a rich class and that is why their parents and the concerned authorities are unable to discipline them the way we should discipline the medical students the same state of affairs is also seen in government colleges throughout the country. I again repeat, there might be, some exceptions to this are there, but overall, in majority of the government medical colleges also there exits shortage of medical teachers and whatever the teachers are there they are also doing the indirect private practice and this indirect private practice results into their running away from the teaching time that is 9 am to 4 $\mathrm{pm}$ duration. They come in the morning, do their sign-in or biometrics, then while going at 4 oclock they again do the biometrics, and no Dean or other authority can control these medical teachers about their from the classes between 9 am to $4 \mathrm{pm}$.

Thirdly, in both the government as well as private colleges, in spite of low attendance, the students are allowed to sit in the University Exam because of some or other pressure whether it is parental pressure or whether it is laxity on the part of authorities of the medical college or because of the government pressure.

These are eye opening areas where you can see that the attendance is hardly 40 to $50 \%$ but still the student is allowed to appear for the examination. Next is that student is not concentrating on proper internal assessment. In many colleges $80-90 \%$ or in some cases $100 \%$ internal assessment is given to very mediocre students.
About pitfalls in private as well as government medical colleges, I can tell you hundreds of examples such that we can write a monograph of about 50 to 100 pages on this issue only. This article is not a scope for that; it will be discussed somewhere else or in some other article.

\section{Challenges}

1. The quantum of doctors available for rural population and for primary health centres who are specially trained to serve in the rural areas is not planned. We must know what number of doctors we need for rural services and what number of specialized doctors we need for the whole country.

2. The policy of postgraduate medical education, especially in respect of selection, is not at all satisfactory, especially in the private medical colleges. In the Government medical colleges the state of affairs is a little bit better.

3. What are we doing to meet the need for rural doctors and post graduate specialists and super specialists, and how we are going to train them?

4. How to decide standards of Indian doctors who will be globally acceptable, while also meeting the local needs of rural and urban society.

These challenges are about the mission of standard medical education and not about the day to day working of doctors in rural or urban areas. 